\title{
Parameter Analysis on shear lag effect of composite girder with steel
}

\section{truss webs}

\author{
Cong Lei ${ }^{1, a}$, Junliang Tian ${ }^{2, b}$, Suisheng $\mathrm{Li}^{2, \mathrm{c}}$, Yingjie Guo ${ }^{2, \mathrm{~d}}$ and Wenjuan $\mathrm{Liu}^{2, \mathrm{e}}$ \\ ${ }^{1}$ Chongqing CPDI Municipal Engineering Co. Ltd, Chongqing, China \\ ${ }^{1} 12$ th Floor, Bihaijindu Building, XinNanLu No.9 ,Yubei District, Chongqing City, China \\ ${ }^{2}$ Highway Administration, Zhengzhou, Henan, China \\ ${ }^{2}$ HangHaiXiLu No.26, Zhengzhou, Henan Province, China \\ a Corresponding author email: congcong1229@126.com, ${ }^{b} g$ ljzgb@126.com, \\ ‘1355066319@qq.com, \\ dyingjieguo99@163.com, ${ }^{\mathrm{e}} 1412268105 @ q q . c o m$
}

Keywords : Steel Truss Webs, Composite Girder Bridge, Finite Element Analysis, Shear Lag Effect

\begin{abstract}
In order to fully understand the shear lag effect variation of concrete composite girder with steel truss webs, the 3D finite element model is established with general finite element software ANSYS, considering three typical load models of mid-span concentrated load, two points symmetrical load and uniform load. The effect of geometric parameters on shear lag effect of simply supported concrete composite girder with steel truss webs is analyzed. Geometric parameters include the span-width ratio, the width-height ratio and wing-thickness ratio. The results show that under three load cases, the influence of the span-width ratio and the width-height ratio on shear lag effect of the prestressed concrete composite girder with steel truss webs was analyzed. The results show that the span-width ratio has greater influence on shear lag effect of the prestressed concrete composite girder with steel truss webs, while the width-height ratio and other parameters have less influence on shear lag effect. And the results indicate that for continuously supported prestressed concrete composite girder with steel truss webs, the negative shear lag effect is quite obvious near the cross-section of mid-support, which needs to attach great importance in the design.
\end{abstract}

\section{Introduction}

Concrete composite girder bridge with steel truss webs concept was first proposed by the French engineer ${ }^{[1]}$. In this structure, the concrete web in the traditional concrete box girder is replaced by steel truss web. Steel truss webs end node directly embedded in concrete top and bottom supporting. The smooth transmission of the force of steel truss and concrete top and bottom plate is constructed by the node. Meanwhile, the structure is also equipped with internal and external prestressed steel. As shown in Fig. 1, the first steel truss composite girder bridge was built in France--Arbois bridge in 1985. Since then, Canada, Singapore, Japan, China and other countries have designed and built a number of concrete composite girder bridges with steel truss webs. Because of its light weight, low cost, beautiful appearance, good wind resistance and other advantages ${ }^{[2]}$, steel truss composite bridge has been fond by more and more bridge engineers and researchers. At present, the researches of concrete composite girder bridge with steel truss webs mainly focus on the two aspects of joint 
and bearing capacity of the whole bridge. Test method is used to study the mechanical behavior of the joint and the whole structure. The results of the test are analyzed and validated by using the finite element numerical simulation. At present, there is less domestic research on concrete composite girder bridge with steel truss webs ${ }^{[3-8]}$. The shear lag effect of simply supported steel truss concrete composite beams under concentrated loads and uniform loads are researched by Shangmin Zheng ${ }^{[2]}$ using ANSYS finite element software. Besides, he analyzed the shear lag effect of composite beam with corrugated steel webs in comparison. Yang Chen ${ }^{[9]}$ analyzed the typical sections shear lag coefficient and effective width of concrete composite girder bridge with steel truss webs by using the spatial entity finite element model, meanwhile he researched the effect of the thickness of the top and bottom plate and the wall thickness of steel truss pipe on the shear lag effect. All of the above studies didn't relate to the effect of the span-width ratio, the width-height ratio and other parameters on the shear lag effect of concrete composite girder bridge with steel truss webs.

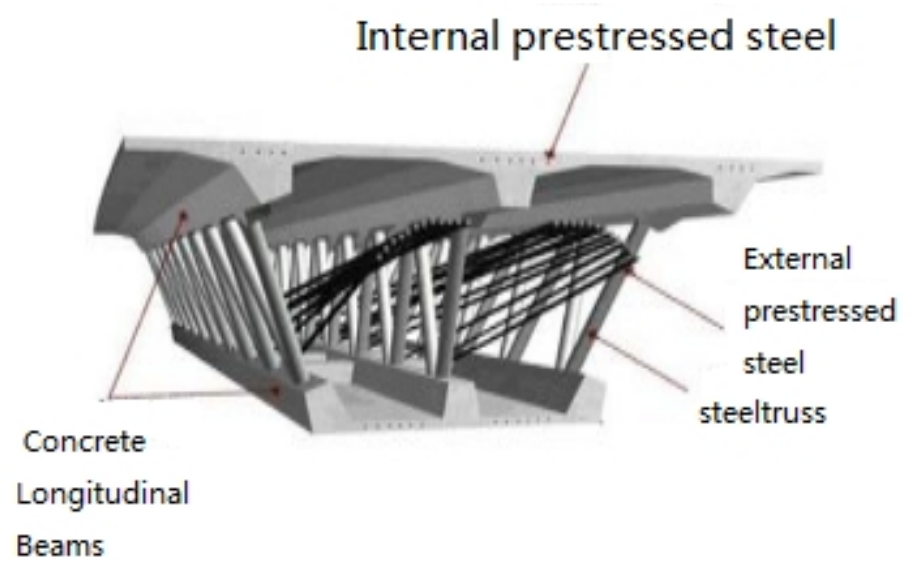

Fig. 1 Concrete composite girder bridge with steel truss webs

In order to deepen the understanding of the shear lag effect of the steel truss composite beam bridge, this paper summarizes the achievements of literature [2] and uses finite element method to research the influence of parameters on shear lag effect of composite girder with steel truss webs .

\section{Concrete Composite Girder Bridge with Steel Truss Webs and Finite Element Model}

In this paper, a simply supported concrete composite girder bridge with steel truss webs as the research object is shown in Fig. 2. The span of simply supported steel truss composite girder concrete composite beam is $35 \mathrm{~m}$. Concrete end beams with longitudinal thickness of $0.925 \mathrm{~m}$ locate both ends of the beam. The top width of the beam section is $8.5 \mathrm{~m}$ and the width of the bottom plate is $4.8 \mathrm{~m}$. The height of the beam is $2.3 \mathrm{~m}$. The thickness of the concrete top is $0.243 \mathrm{~m}$ and the bottom plate thickness is $0.22 \mathrm{~m}$. Section form and size are shown in Fig. 3. Concrete top plate and bottom plate use C50 concrete and the modulus of elasticity is $3.45 * 104 \mathrm{MPa}$. Steel truss use the Q420E grade steel, the modulus of elasticity is $2.06 * 105 \mathrm{MPa}$. The size of steel pipe is $351 * 16 \mathrm{~mm}$ and the steel pipe wall thickness is $16 \mathrm{~mm}$. The angle between axis of the steel pipe and the longitudinal axis of the bridge is 67 degrees and the pitch is $1.95 \mathrm{~m}$. 


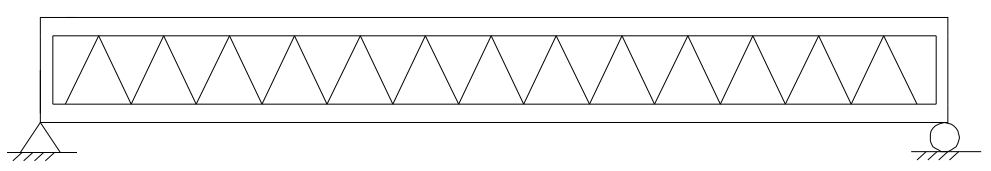

Fig. 2 Bridge elevation

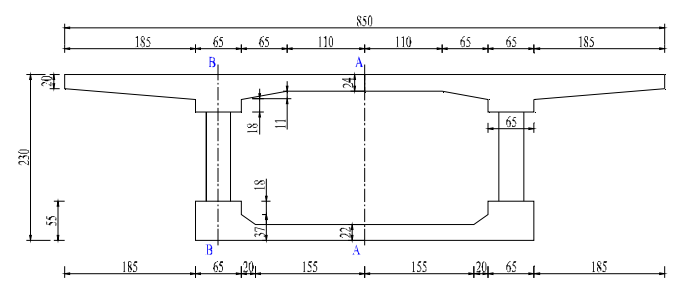

(a) Cross section

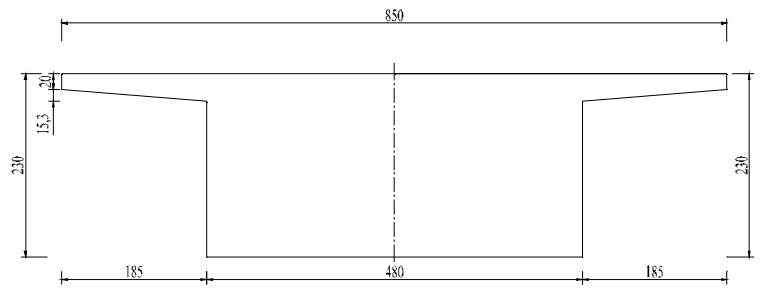

(b) End section

Fig. 3 section structure (Unit:cm)

The finite element model of simply supported concrete composite girder bridge with steel truss webs is established using ANSYS finite element software, as shown in Fig. 4. The concrete top and bottom plates are simulated by solid 45 unit, and the steel tube is simulated by beam188 unit. The end of the steel pipe is directly inserted into the top and bottom of the concrete. The relative slip between the steel tube and concrete is not considered. The beam188 unit and the solid45 unit are coupled at the connection positions.

Considering three typical loads, such as mid-span concentrated load ( $\mathrm{P}=1000 \mathrm{kN})$,two points symmetrical load $(\mathrm{F}=1000 \mathrm{kN})$ and uniform load $\mathrm{q}=100 \mathrm{kN} / \mathrm{m})$. The mechanical performance about the simply supported concrete composite girder bridge with steel truss webs under three typical loads is analyzed.

The cross section shown in Fig. 5 is analyzed. 10 representative cross sections are selected along the longitudinal direction of the beam. Among the 10 sections, 5 cross sections are selected from 1/4 $\operatorname{span}(\mathrm{a}, \mathrm{b}, \mathrm{c}, \mathrm{d}, \mathrm{e})$ and the other 5 cross sections are selected in a single section of the middle span ( $a, b, c, d, e)$. Select section center line position ( Fig. 3 ( a ) A-A ) and web support position (Fig. 3 ( a ) B-B ) in the transverse section from the 10 representative cross sections.

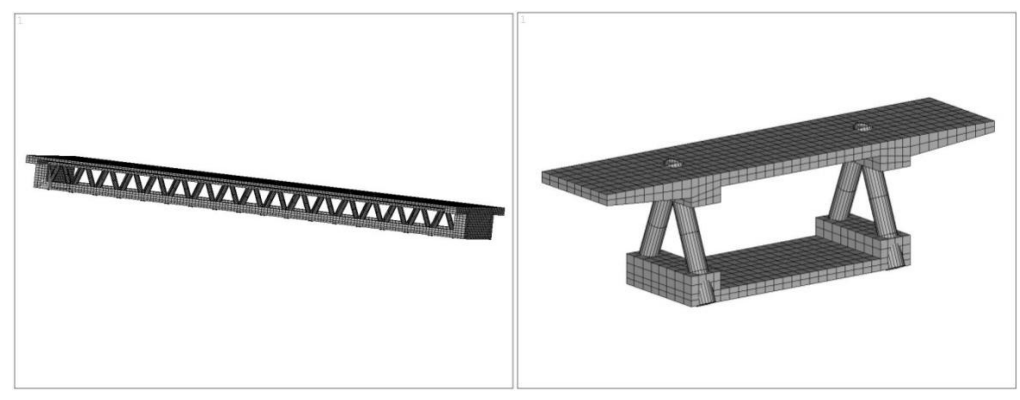

(a) Entity model

(b) General segment

Fig. 4 Concrete composite girder bridge with steel truss webs finite element model 


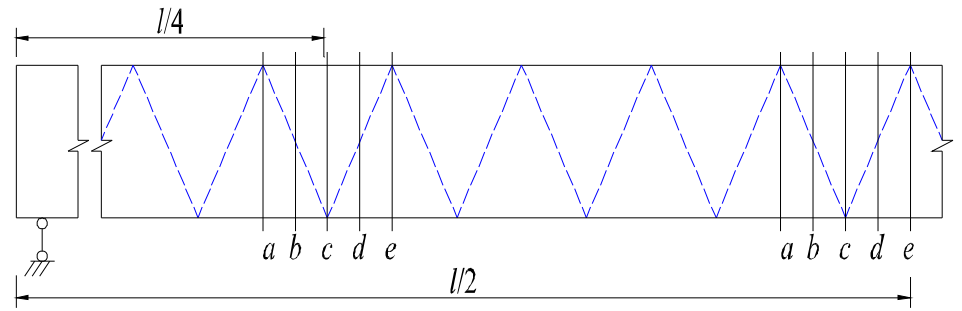

Fig. 5 The analysis section of the longitudinal position map

\section{Influence of Geometric Parameters on Shear Lag Effect of Simply Supported Concrete Composite Girder Bridge with Steel Truss Webs}

In order to analyze the shear lag effect variation of concrete composite girder with steel truss webs more accurately, this section considers three typical load models of mid concentrated load, two symmetrical load and uniform load. Analyze the influence of geometric parameters on shear lag effect of simply supported concrete composite girder with steel truss webs. Geometric parameters include span-width ratio, the width-height ratio and wing-thickness ratio. The mid-span cross section should be analyzed under the concentrated load. Under symmetrical load the selected cross section is $1 / 4$-span section. The obtained cross sections should be adjacent to the mid-span section under the uniformly load.

Span-width Ratio (l/b). To study the influence of span-width ratio on the shear lag effect of steel truss composite beams, keeping section width $b$ constant and changing span 1 to make the $1 / b$ change from 3 to 8 and the tolerance is 0.5 . The 12 groups of simple supported steel truss composite beams with different spans are set up. The relationship between the shear lag coefficient and the span-width ratio $1 / \mathrm{b}$ is obtained, as shown in Fig. 6, Fig. 7 and Fig. 8.
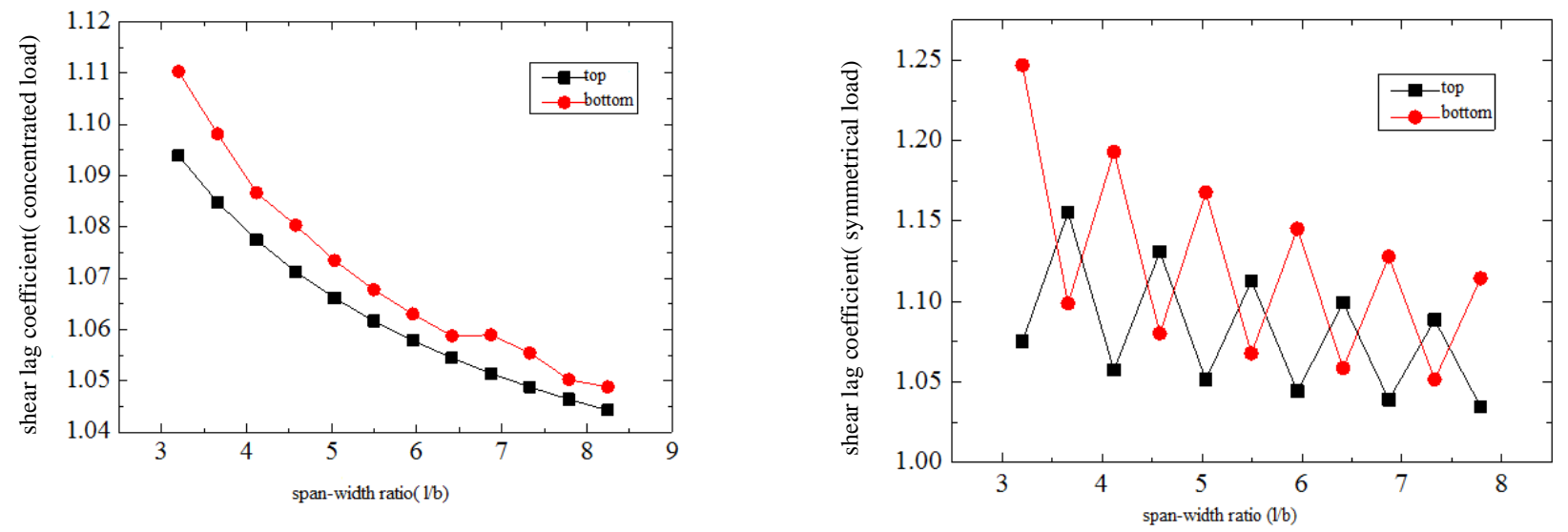

Fig. 6 The variation of shear lag coefficient $\quad$ Fig. 7 The variation of shear lag coefficient with with the span-width ratio $1 / \mathrm{b}$ under the width- span ratio $1 / \mathrm{b}$ under the symmetrical load concentrated load

Seen from Fig. 6, the shear lag coefficient decreases from 1.11 to 1.04 when the span-width ratio increases from 3 to 8 under the concentrated load. The shear lag coefficient decreases with the increase of the span-width ratio $1 / b$. It shows that the shear lag effect of concrete composite girder with steel truss webs gradually reduce when the span becomes large.

From Fig. 7, under four points symmetrical load, the shear lag coefficient of top increases with 
the increase of span-width ratio $1 / b$, the value oscillates between $1.11 \sim 1.25$, and the overall trend to decrease. The shear lag coefficient of bottom plate increases with the increase of span-width ratio $1 / b$, the coefficient oscillates between 1.05 1.1. Overall there is a trend of decrease.

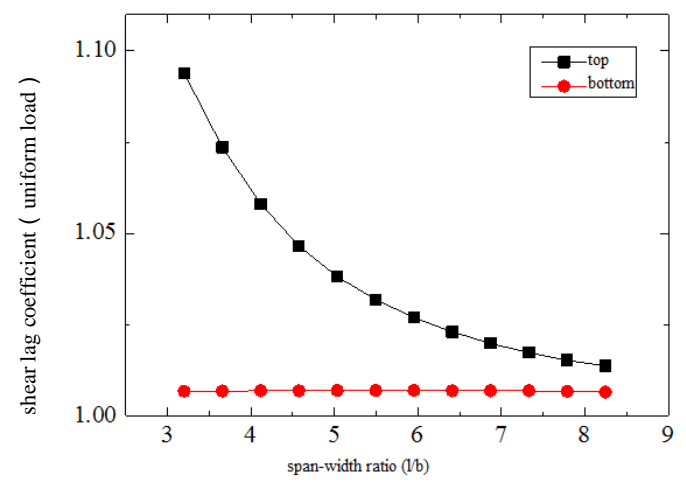

Fig. 8 The variation of shear lag coefficient with span-width ratio $1 / b$ under uniform load

It can be seen from Fig. 8 that under uniform load, span-width ratio has great influence on the shear lag effect of top of the concrete composite girder. When the span-width ratio increases, the shear lag coefficient decreases rapidly. When the span-width ratio $1 / \mathrm{b}$ increased from 3 to 6 , the shear lag coefficient decreases at a higher rate. When the span width ratio $1 / b$ is greater than 7 , the variation of shear lag coefficient with the span-width ratio tends to be gentle. Under the uniform load, the bottom shear lag coefficient is not affected, and the influence of span-width ratio on shear lag coefficient is also small.

Width-height Ratio(b/h). Fetch the width-span ratio b/l equals 4 and width-height ratio equals 3, 4, 5 and 6 , then analyze the variation of shear lag coefficient of the simply supported concrete composite girder with steel truss webs.

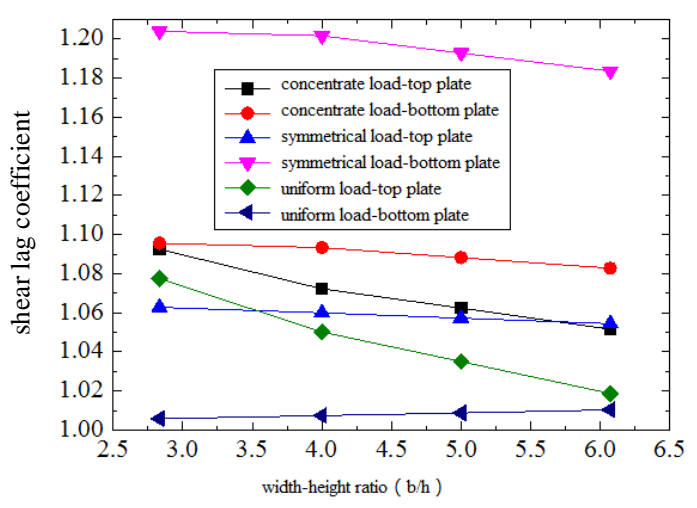

Fig. 9 Effect of width-height ratio $\mathrm{b} / \mathrm{h}$ on shear lag coefficient

It can be seen from Fig. 9 that under the action of concentrated load and symmetrical load, the width-height ratio ratio b/h varies from 3 to 6 and the shear lag coefficients of the top and bottom are not affected basically .Under uniform load, the shear lag coefficient decreases slightly with the increase of width-height ratio $b / h$. When the width-height ratio ratio $b / h$ varies from 3 to 6 , the shear lag coefficient changed from 1.08 to 1.02 . The shear lag coefficient is almost not affected by the bottom plate .It can be considered, the effect of width-height ratio on the shear lag coefficient of simply supported steel truss concrete beams is small and the effect of the aspect ratio on the shear lag effect can not be considered. 
Wing-thickness Ratio(b1/t). In order to study the effect of section stiffness on the shear lag, this section analyzes the influence of wing-thickness ratio $b_{1} / t$ on shear lag coefficient. When the span-width ratio $1 / \mathrm{b}$ equals 4 , and width-height ratio $\mathrm{b} / \mathrm{h}$ is 3.6 ( $\mathrm{b} 1$ is half of the center line of the web on the top of the concrete, $t$ is the thickness of top or bottom plate of the concrete). Changing the thickness of bottom plate varies from 40 to 15, so the wing-thickness ratio varies from 6 to 16 .

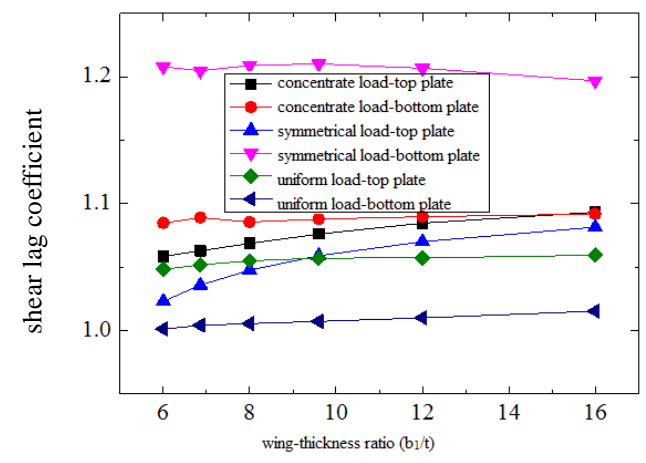

Fig. 10 Wing-thickness ratio b1/t influence on shear lag coefficient

The variation of shear lag coefficient changes with the wing-thickness ratio of the steel truss composite beams is shown in Fig. 10. It can be seen from Fig. 10 that the wing thickness ratio increased from 6 to 16 under the symmetrical load. The shear lag coefficient of the top plate has a slight increment and changes from 1.02 to 1.08. Under the action of the concentrated load or uniform load, the shear lag coefficient of the top and bottom plate is not changed. It can be considered that the effect of wing-thickness ratio on the shear lag coefficient is very small and the influence of wing-thickness ratio is not considered when analysing the influence of shear lag effect on the concrete composite girder bridge with steel truss webs.

\section{Conclusions}

In this paper, the three-dimensional solid model is established using the finite element software ANSYS, considering three typical loads of mid-span concentrated load, two points symmetrical load and uniform load. This paper also analyzes the effect of structural geometric parameters of span-width ratio and width-height ratio on shear lag effect of simply supported steel truss composite beams. The main conclusions are as followed. Under the three loads of concentrated load, symmetrical load and uniform load, the span-width ratio $1 / b$ has great influence on the shear lag effect of simply supported steel truss composite beams. But the width-height ratio and wing-thickness ratio have little impact on the shear lag coefficient of simply supported steel truss concrete beams. So the effect of width-height ratio on the shear lag effect can not be considered.

\section{References}

[1] Fusheng Huang and Yuqing Liu. Structural Characteristics of the Composite Truss Bridge [C]. In: Proceedings of the National Conference on Bridge Engineering. November 52007 , Guangzhou, Guangdong, P. R. China. In Chinese

[2] Shangmin Zheng, Shui Wan. Journal of Highway and Transportation Research and Development, 2013(11) : P68-P72. In Chinese

[3] Li Yan, Zhengting Yan. Handbook of calculation and construction of steel and concrete composite structures [M]. Beijing, P. R. China, China Architecture \& Building Press, 1996. In Chinese

[4] Kwang S K, Kwang H J, Chung W S. Behavior of prestressed concrete hybrid girder bridge with 
steel web according to connection system[R]. 2008.

[5] Yingying Zhang. Experimental study and theoretical analysis of steel truss web prestressed concrete composite beam bridge nodes [D]. Thesis, Nanjing Tech University, P. R. China, 2012. In Chinese

[6] Jung K, Kim J J, Yi J, et al. Development and Evaluation of New Connection Systems for Hybrid Truss Bridges[J]. Journal of Advanced Concrete Technology. 2013, 11(2): 61-79.

[7] Liu Y, Xin H, He J, et al. Experimental and analytical study on fatigue behavior of composite truss joints[J]. Journal of Constructional Steel Research. 2013, 83: 21-36.

[8] Machacek J, Cudejko M. Longitudinal shear in composite steel and concrete trusses[J]. Engineering Structures. 2009, 31(6): 1313-1320.

[9] Chen Yang. Study on mechanical performance and design method of concrete composite girder bridge with steel truss webs [D]. Southeast University, P. R. China, 2011. In Chinese 